http://www.jfas.info

\title{
APPLICATION OF QUANTITATIVE AND QUALITATIVE METHODS FOR DETERMINATION OF PRIORITY DEVELOPMENT DIRECTIONS OF COMPANIES IMPLEMENTING LEAN MANUFACTURING
}

\author{
Y. G. Shtefan*, L. A. Zimakova, S. N. Kovalenko, N. N. Peresypkina
}

Belgorod State University Russia, 308015, Belgorod, Russia, Pobeda str.85

Published online: 15 February 2017

\begin{abstract}
This article covers the issues of integration of qualitative and quantitative methods applied when justifying management decision-making in companies implementing lean manufacturing. The authors defined goals and subgoals and justified the evaluation criteria which lead to the increased company value if achieved. The authors identify the most important top-level rating indicators: receiving a profit and increase in cash flow. The lower level includes criteria: 1) created value, sales volume, productivity, customer satisfaction; 2) net cash flow, turnover of current assets, EBITDA; 3) amount of accounts receivable; acceleration of the time from receipt of the order to receipt of money, expansion of own dealer network; 4) loss reduction, reduction of indirect costs, reducing inventory. The application of the analytic hierarchy process and the involvement of experts of various services allow accelerating management decision-making with regard to the determination of the priority development directions in the current economic conditions and making the process objective to the maximum.
\end{abstract}

Keywords: analytic hierarchy process, lean manufacturing, management accounting, decision-making

Author Correspondence, e-mail: zimakova@bsu.edu.ru

doi: http://dx.doi.org/10.4314/jfas.v9i1s.748 


\section{INTRODUCTION}

The study methods applied in various fields of expertise are rather diverse and continuously developing. Economics belongs to social life. It relates to the society, a human and all aspects of human life and activity. Economic entities that implement up-to-date production and management methods cannot immediately solve all the problems they face, therefore it is necessary to determine the sequence of solution thereof. For these purposes, an integrated approach based on the opinions of experts of various services of the economic entity (sales department, production and technical department, economics department, administrative department, etc.) shall be applied.

Lean manufacturing is one of the new up-to-date approaches. Its philosophy stipulates changing the perception of business and focusing on cost reduction by decreasing various losses. This study was based on the determination of priority criteria using lean manufacturing principles.

To solve the task assigned, the analytic hierarchy process which is actively used by experts of various fields was selected. The founder of this method is T. Saaty (Saaty, 1993), but the current method was developed by domestic authors: A.N. Borisov (Borisov, 2012), V.V. Davnis (Davnis, 2005), V.A. Kalugin, O.S. Pogarskaya and O.I. Malykhina (2013), E.V. Romanenko (2015) and others. Its advantage is in the use of mathematical tools which, on the one hand, exclude subjectivity and, on the other hand, allow considering expert opinions.

The primary task of this study is to determine the sequence of achievement of goals and subgoals and develop performance evaluation criteria hierarchies for the company implementing lean manufacturing based on the opinions of qualified experts and using mathematical tools.

\section{METHODOLOGY}

The study of lean manufacturing principles, collection, grouping, compilation of information on the practice of application of these principles, survey of employees of various business units of the companies under study allowed determining the efficiency criteria typical of lean manufacturing. The analysis and synthesis of up-to-date management accounting systems made it possible to develop a correct hierarchy of criteria. Upon determination thereof, the measurability and reality of the evaluation of facts and events were considered.

Quantitative data are number system elements, so based on the analysis thereof their properties and dependencies that will be preserved under certain conditions can be 
determined. Therefore, the expert evaluation method was used for the interpretation of the selected criteria into quantitative values.

Based on the data obtained, pairwise comparison matrices were developed, and for the evaluation of consistency of results, the eigenvector of the matrix row was developed, which is calculated by dividing the geometric mean in the row into the sum of the geometric mean of all rows. Formula (1) was used for the calculation of the geometric mean:

$$
G\left(X_{1}, X_{2}, X_{3} \ldots X_{n}\right)=\sqrt[n]{\sqrt[n]{X^{1}}, X_{2}, X_{3} \cdots} \bar{X}_{n}=\left(\prod_{\substack{i=1 \\ m h e r}}^{n} x_{i}{ }^{1 / n}\right.
$$

The division of the sum of components of this vector into the number of components gave the main eigenvalue of the matrix ( $\lambda \max$ ) which can be used for the evaluation of consistency that reflects the proportion of preferences.

When comparing the number of objects in the matrix and $\lambda \max$, the conclusion on consistency of the result can be made. In cases where the number of objects and the main eigenvalue are equal, a completely consistent result is obtained. To evaluate consistency, the deviation from consistency (consistency index (CI) which is calculated based on formula (2)) is calculated:

$$
\mathrm{CI}=\frac{\left.\lambda_{\text {max }}-\mathrm{n}\right)}{(\mathrm{n}-1)}
$$

where $\mathrm{n}$ is the number of objects in the matrix. If the consistency index value is less than or equal to 0.1 , the judgment is satisfactory.

The random index (RI) is a constant value. It depends on the number of elements in the matrix (if $2, \mathrm{RI}=0$; if $7, \mathrm{RI}=1.32$; if $9, \mathrm{RI}=1.45$ ). The ratio of $\mathrm{CI}$ to average $\mathrm{RI}$ for the same-order matrix is called the consistency ratio (CR). The CR value that is less than or equal to 0.10 is considered acceptable.

As a result, the conclusion was made on the complete consistency of matrices of pairwise comparison matrices at all levels, which made it possible to develop the matrix of priorities between alternatives.

The combination and integrated use of quantitative and qualitative methods allowed for the partial elimination of subjectivism upon management decision-making and accelerated the process of selection of priority indicators for a particular entity. 


\section{RESULTS}

The study conducted allowed to identify the following phases of determination of priority criteria for the evaluation of companies implementing lean manufacturing.

The first phase: definition of goals and development of criteria hierarchies. The ultimate goal of operation of any economic entity is the increased value, which depends on the profit and ability to accumulate cash funds. The company's ability to accumulate cash funds affects not only liquidity and solvency but is also essential for the increase in the company value (Michalsk, 2010). Therefore, two most important sub goals were identified for economic entities: obtaining profits, cash flow.

In terms of profit increase, the following criteria can be determined as part of the lean manufacturing concept: value created, sales volume, productivity, customer satisfaction. The criteria enabling the accumulation of the cash flow include the calculated indicators: net cash flow, turnover of current assets, EBITDA. The financial result of the entity directly depends on cash proceeds which, in turn, are determined by lower order indicators: accounts receivable amount, acceleration of time from order placement to the receipt of funds, the expansion of own dealer network. The simplest evaluation criterion is expenses, which minimization is sought by each entity. The most important tasks solved as part of cost reduction include: decrease of losses, reduction of overhead expenses, and reduction of stocks. Customer focus requires continuous implementation of measures in the field of improvement of quality of products, production processes, and management.

All the foregoing allows determining the hierarchy of goals and subgoals and the most significant criteria, as shown in Figure 1.

The first level of the hierarchy stipulates the determination of criteria for the evaluation of alternatives and contains specific subgoals (1-7). 


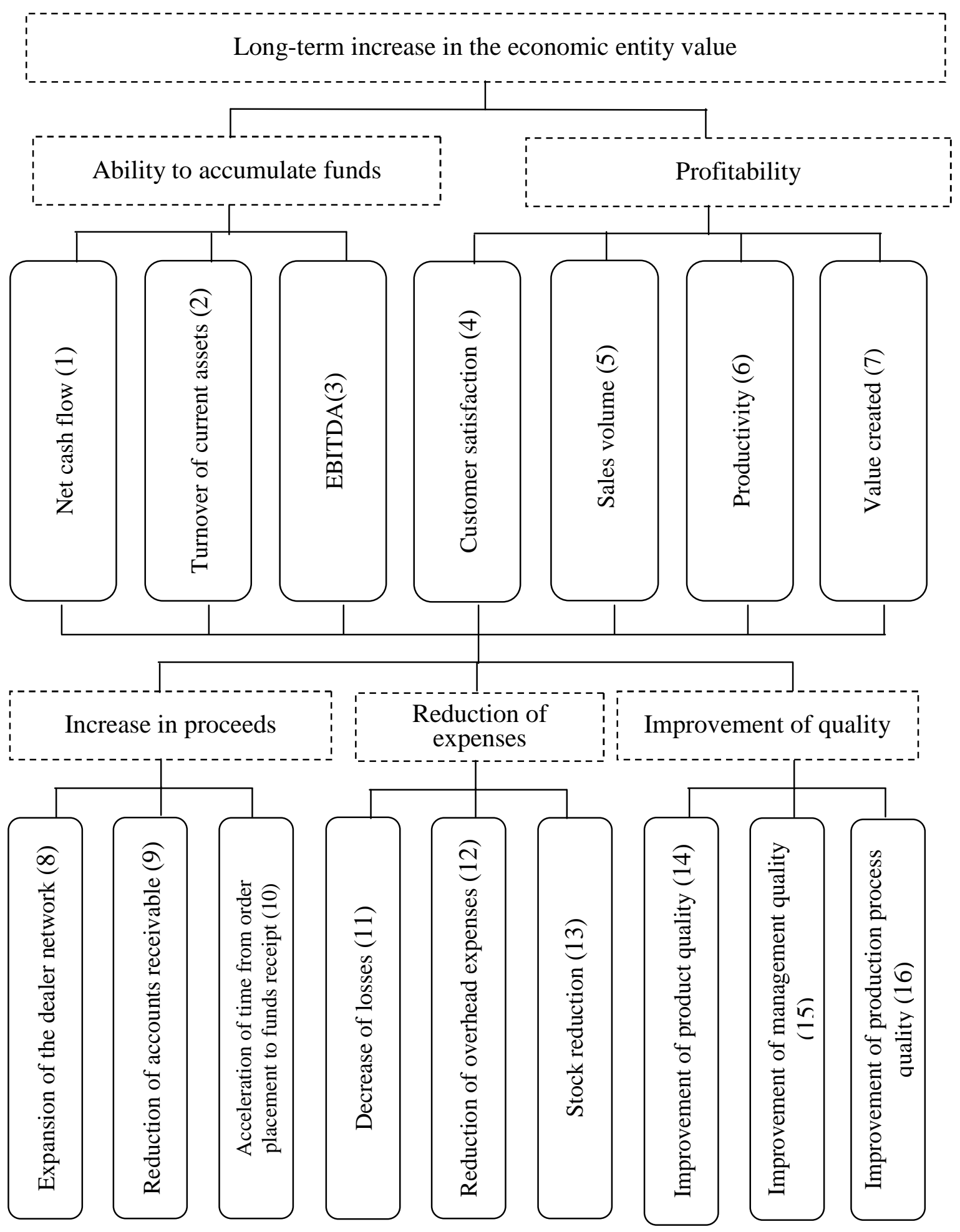

Fig.1. Hierarchy of criteria affecting the long-term increase in the economic entity value

The second level includes the determination of options of increase in the economic entity value (8-16).

The second phase. Selection of experts and evaluation of the degree of prevalence of one alternative over another one. The survey conducted allowed to select as experts: financial 
managers; heads of production and technical departments; customer service managers; economic forecasters.

Based on the decision-making level, the opinions of various experts are used. When comparing upper-level scenarios, managers were involved as experts and a standard preference scale was used. Rank variables were used as the basis for the comparison procedure and development of the preference matrix during the evaluation.

The third phase: development of pairwise comparison matrices of the criteria prevalence, as well as pairwise comparison matrices of alternatives. Based on expert evaluations, matrices similar to those given in Table 1 were developed.

Table 1. Pairwise comparison matrix of criteria prevalence

\begin{tabular}{|c|c|c|c|c|c|c|c|c|c|c|}
\hline $\begin{array}{c}\text { Criteria } \\
\text { selectio } \\
\mathrm{n}\end{array}$ & 1 & 2 & 3 & 4 & 5 & 6 & 7 & $\begin{array}{c}\text { Geometri } \\
\text { c mean }\end{array}$ & $\begin{array}{c}\text { Matrix } \\
\text { eigenvecto } \\
\mathrm{r}\end{array}$ & Rank \\
\hline 1 & $\begin{array}{c}1.0 \\
0\end{array}$ & 4.00 & 2.00 & 5.00 & 0.50 & 6.00 & 3.00 & 2.32 & 0.24 & 2 \\
\hline 2 & $\begin{array}{c}0.2 \\
5\end{array}$ & 1.00 & 0.33 & 2.00 & 0.20 & 3.00 & 0.50 & 0.65 & 0.07 & 5 \\
\hline 3 & $\begin{array}{c}0.5 \\
0\end{array}$ & 3.00 & 1.00 & 4.00 & 0.33 & 5.00 & 2.00 & 1.53 & 0.16 & 3 \\
\hline 4 & $\begin{array}{c}0.2 \\
0\end{array}$ & 0.50 & 0.25 & 1.00 & 0.17 & 2.00 & 0.33 & 0.43 & 0.04 & 6 \\
\hline 5 & $\begin{array}{c}2.0 \\
0\end{array}$ & 5.00 & 3.00 & 6.00 & 1.00 & 7.00 & 4.00 & 3.38 & 0.35 & 1 \\
\hline 6 & $\begin{array}{c}0.1 \\
7\end{array}$ & 0.33 & 0.20 & 0.50 & 0.14 & 1.00 & 0.25 & 0.30 & 0.03 & 7 \\
\hline 7 & $\begin{array}{c}0.3 \\
3\end{array}$ & 2.00 & 0.50 & 3.00 & 0.25 & 4.00 & 1.00 & 1.00 & 0.10 & 4 \\
\hline $\begin{array}{c}\text { Sum of } \\
\text { table } \\
\text { element } \\
\text { s }\end{array}$ & $\begin{array}{c}4.4 \\
5\end{array}$ & 15.83 & 7.28 & 21.50 & 2.59 & 28.00 & 11.08 & 9.61 & 1.00 & $\mathrm{x}$ \\
\hline
\end{tabular}

The fourth phase: determination of consistency of results. The results of all calculations based on the above formulas are given in Table 2. 
Table 2. Evaluation of consistency of results

\begin{tabular}{|c|l|c|c|c|c|c|}
\hline \multirow{2}{*}{ Levels } & \multicolumn{1}{|c|}{ Name } & $\lambda \max$ & $\mathrm{n}$ & $\mathrm{CI}$ & $\mathrm{RI}$ & $\mathrm{CR}$ \\
& & & & & & \\
\hline \multirow{2}{*}{1} & Criteria (1-7) & 7.2013 & 7.0000 & 0.0336 & 1.3200 & 0.0254 \\
\hline \multirow{2}{*}{2} & Net cash flow (1) & 9.4151 & 9.0000 & 0.0519 & 1.4500 & 0.0358 \\
\cline { 2 - 7 } & Turnover of current assets (2) & 9.4108 & 9.0000 & 0.0514 & 1.4500 & 0.0354 \\
\cline { 2 - 7 } & EBITDA (3) & 9.4075 & 9.0000 & 0.0509 & 1.4500 & 0.0351 \\
\cline { 2 - 7 } & Customer satisfaction (4) & 9.4246 & 9.0000 & 0.0531 & 1.4500 & 0.0366 \\
\cline { 2 - 7 } & Sales volume (5) & 9.5714 & 9.0000 & 0.0714 & 1.4500 & 0.0493 \\
\cline { 2 - 7 } & Productivity (6) & 9.3759 & 9.0000 & 0.0470 & 1.4500 & 0.0324 \\
\cline { 2 - 7 } & Value created (7) & 9.3984 & 9.0000 & 0.0498 & 1.4500 & 0.0343 \\
\hline
\end{tabular}

The evaluation results allow concluding on the complete consistency of pairwise comparison matrices at all levels.

The fifth phase: synthesis of the decision results.

This phase stipulates weighing of normalized eigenvectors of alternatives using the criteria weights obtained during the third phase, which are contained in the eigenvector-column of pairwise comparisons of criteria prevalence. For convenience of calculations, the normalized eigenvectors of alternatives are summarized in the matrix of priorities between the alternatives in Table 3 .

Table 3 . Matrix of priorities between alternatives

\begin{tabular}{|c|c|c|c|c|c|c|c|}
\hline \multirow{2}{*}{ Alternatives } & \multicolumn{7}{|c|}{ Criteria } \\
\cline { 2 - 8 } & 1 & 2 & 3 & 4 & 5 & 6 & 7 \\
\hline 8 & 0.3081 & 0.1087 & 0.2258 & 0.0179 & 0.3143 & 0.0748 & 0.0511 \\
\hline 9 & 0.2235 & 0.2241 & 0.1081 & 0.0344 & 0.0252 & 0.0512 & 0.0248 \\
\hline 10 & 0.0509 & 0.1536 & 0.0246 & 0.2229 & 0.1601 & 0.0249 & 0.0353 \\
\hline 11 & 0.0743 & 0.0511 & 0.0351 & 0.1081 & 0.0758 & 0.2249 & 0.3092 \\
\hline 12 & 0.1570 & 0.0180 & 0.3073 & 0.0246 & 0.0189 & 0.0180 & 0.1088 \\
\hline 13 & 0.1084 & 0.3090 & 0.0176 & 0.0508 & 0.0519 & 0.0354 & 0.0180 \\
\hline 14 & 0.0352 & 0.0361 & 0.1566 & 0.3073 & 0.0878 & 0.1091 & 0.2243 \\
\hline 15 & 0.0247 & 0.0248 & 0.0741 & 0.0741 & 0.0452 & 0.2964 & 0.1506 \\
\hline 16 & 0.0179 & 0.0745 & 0.0508 & 0.1598 & 0.2208 & 0.1653 & 0.0780 \\
\hline
\end{tabular}

Multiplication of the matrix (Table 3) by the vector column gives an evaluation of alternative options of the long-term increase in the economic entity value, the results of which are given in Table 4. 
Table 4. Alternative evaluation results

\begin{tabular}{|c|c|c|}
\hline Alternatives & Evaluated value & Rank \\
\hline 8 & 0.2367 & 1 \\
\hline 9 & 0.1009 & 5 \\
\hline 10 & 0.0974 & 7 \\
\hline 11 & 0.0976 & 6 \\
\hline 12 & 0.1077 & 8 \\
\hline 13 & 0.0734 & 4 \\
\hline 15 & 0.1073 & 9 \\
\hline 16 & 0.0635 & 2 \\
\hline
\end{tabular}

The calculations made showed that the priority direction is the expansion of the dealer network (0.2367), improvement of the quality of production processes $(0.1155)$, while special attention shall be paid to the reduction of overhead expenses (0.1077). Therefore, these directions can be recommended as the most preferable ones.

The expansion of own dealer network will approximate the producer to the customer and allow for better management of the range and production volumes, taking into account the customer needs. This will also lead to the increased cash proceeds due to the increased number of customers and accelerated document flow. Simultaneous work on the improvement of the quality of production processes can be performed in order to reduce overhead expenses.

\section{DISCUSSION}

Today, the issues of combination of qualitative and quantitative study methods are often raised, and management accounting is no exception (Modell, 2007). The application of only quantitative (mathematical-statistical) methods allows identifying trend-indicating links between the variables. However, it may be insufficient for explanation of reasons. There are rather complex cause-effect relationships in the economic sector: new factors may appear and known factors may vary, the influence of which, in combination with others, cannot be always predicted. Therefore, this study is based on the combination of quantitative and qualitative methods applied upon information support of decision-making.

The next major challenge is the development of the hierarchy of criteria. The refocus of economic entities on customers not only for the purpose of satisfaction of their needs but also for the purpose of increasing profits predetermines the required reorientation of the management system from the solution of tactical tasks to the achievement of strategic goals (Zimakova, 2016). Lean manufacturing is focused on the evaluation of value streams and 
stipulates the combination of different criteria. However, it is also important that the results are clearly defined, standardized and reported to contractors. Such authors as N.V. Golyshev and V.E. Kireev (Golyshev, 2014), N.V. Kotelnikova (Kotelnikova, 2013), Y.I. Volochaeva and I.V. Nagulina (Volochaeva, 2013), S.G. Glukhov (Glukhov, 2016) and others consider it necessary to apply the differentiated system of criteria that are preliminary evaluated based on a score scale.

Maskell B. and Kennedy F. (Maskell, 2007) distinguish the following essential tasks of lean manufacturing: delivery of products to the customer within the shortest possible terms; quick receipt of money; minimum product cost; increase in profitability; reduction of stock volume. The studies conducted by I. Masaaki (Masaaki, 1986) showed that the American approach to evaluation is focused on the result, which can be measured and relates to obtaining profits, and the Japanese approach differs in focus on the process and desire to improve results.

This phase reveals the problem between the evaluation criteria in terms of indicators reflected in financial statements and indicators showing the prospects for growth and development of the economic entity. (Zimakova, 2017). Therefore, it is necessary to develop a set of indicators that allow giving an objective evaluation of both processes and employees (managers and workers) involved in the processes used in the management accounting system.

Debra Stone (Stone, 2014) draws attention to the fact that if the actual results (evaluated based on historical costs) are compared with the planned indicators, it does not give better results in most cases. It shall be considered that the historical cost of non-current assets used in the manufacture of products is not changed; therefore, the element of costs included in the net cost as depreciation is also not changed.

When describing lean manufacturing, Womak, J., Jones, D., \& Adler, Y. (Womak, 2004) draw attention to the fact that it is a dynamic process of changes caused by the systematic set of principles and best practices aimed at continuous improvement. They believe that the fundamental principle is the continuous improvement of production processes; therefore this indicator can be selected as the most essential one.

Quantitative data are number system elements, so based on the analysis thereof their properties and dependencies that will be preserved under certain conditions can be determined (Kantardzhyan,2016). Mathematical methods are easily applicable in the presence of quantitative values, however, in this case non-numerical information is used, which creates certain difficulties and assumes certain assumptions and conventions. E.N. Kamyshanchenko, 
V.V. Davnis, M.V. Selyukov, N.P. Shalygina and N.F. Sivtsova (2015) recommend using expert evaluations when using non-numerical information.

While reviewing the issues of use of expert evaluations, Kaspina, R.G., Molotov, L.A., Kaspin, L.E. (2015) report on the difficulties occurred as part of forecasting of cash flows as the integrated reporting element during the selection of experts who shall reduce risks of faulty evaluation by using their experience.

\section{CONCLUSION}

The use of quantitative methods creates the basis for the objective evaluation of factors, and qualitative methods make it possible to identify cause-effect relationships. This forms the basis for considering the possible use of the analytic hierarchy process when making decisions on the priority directions and indicators used as evaluation criteria at various phases of implementation of lean manufacturing. Based on the primary objective of the business company which stipulates the increase in company value, the following subgoals were defined: improvement of the ability to accumulate cash and increase in profitability. The first subgoal achievement criteria include: net cash flow, turnover of current assets, EBITDA. The profitability is affected by customer satisfaction, productivity, sales volume, value created. The more thoroughly review of the problem made it possible to identify lower order factors that affect the solution of the tasks assigned. Mathematical calculations allowed determining the priority of indicators and identifying the most significant tasks: expansion of the dealer network, improvement of the quality of production processes and reduction of overhead expenses. All these tasks can be solved simultaneously, which makes it possible to improve the economic entity performance within the acceptable terms.

\section{RESULTS}

The idea of an integrated combination of quantitative and qualitative methods was realized by using the analytic hierarchy process to make decisions on determining priority performance criteria for companies that implementing lean manufacturing. To do this, it has been identified goals, sub-goals and the most important criteria that will achieve optimal results at each stage of the implementation of lean manufacturing. A correct assessment can be given by attracting experts from some areas of knowledge: financial managers; heads of the production and technical department; managers of the customer service; economists-analysts, who can evaluate the priorities of development directions from different sides. The use of quantitative 
methods made it possible to determine the priorities more objectively, which is confirmed by mathematical calculations.

\section{REFERENCES}

Borisov, A.N. (2012). Rating evaluation in risk conditions: Ed. V.V. Davnis. - Moscow, Vash Poligraficheskiy Partner Publishing House. (In Russian)

Davnis, V.V. (2005). Forecast models of expert preferences: Voronezh: Publishing House of the Voronezh State University. (In Russian)

Glukhov, S.G. (2016). Method of promotion of labor of agricultural employees on the basis of collective expert evaluations. Laws of development of regional agrofood systems, 1: 172176. (In Russian)

Golyshev, N.V., Kireev V.E. (2014). Analysis of approaches to the evaluation of parameters of labor efficiency and salary of employees of the educational sector in conditions of economic transformation. Naukovedenie Online Journal, 6 (25): 72. (In Russian)

Kalugin, V.A., Pogarskaya O.S, Malikhina I.O. (2013).The Principles and Methods of the Appraisal of Commercialization Projects of the Universities Innovations. World Applied Sciences Journal, 25(1): 97-105.

Kamyshanchenko, E.N., Davnis, V.V., Selyukov, M.V , Shalygina, N.P. and Sivtsova, N.F.(2015). Design of the Maps of Commercial Risks of Managing Metallurgical Production in Russia on the Basis of Alternative Scheduling Solutions. International Business Management, 9(6):1190-1193.

Kantardzhyan, S.L., Rafyan, T.A. (2016).Improving the management ofchemicaltechnological system (CTS) with the use of econometrical models. Research Result. Economic Research,4. [Web-page]. Access mode: http://researchresult.ru/en/economic/annotation/954/(In Russian)

Kaspina, R.G., Molotov, L.A., Kaspin, L.E. (2015).Cash flow forecasting as an element of integrated reporting: an empirical study. Asian Social Science, 11: 89-94.

Kotelnikova, N.V. (2013). Conceptual approaches to the evaluation of labor efficiency of employees. Current development of economic and legal relations. Education and educational activity, 2013, 64-69. (In Russian)

Masaaki, I. (1986). Kaizen: The key to Japan's competitive success. New York : McGrawHill.

Maskell, B. \& Kennedy, F. (2007).Why do we need lean accounting and how does it work? The Journal of Corporate Accounting \& Finance, March/April 59-73. 
Michalski, G.(2010) Planning optimal from the firm value creation perspective levels of operating cash investments. Romanian Journal of Economic Forecasting 13(1):198-214.

Modell, S, Morris, R, Scapens, B.(2007). Mixing Qualitative and Quantitative Methods in Management Accounting Research: A Critical Realist Approach [Web-page]. Access mode: http://papers. ssrn. com/sol3/papers. cfm.

Romanenko, E.V. (2015). Selection of the financial strategy of organization of the dairy processing industry using the analytic hierarchy process (based on the example of the Ulyanovsk region). Economics and Entrepreneurship, 6-3 (59-3): 296-302. (In Russian)

Saaty, T. (1993). Decision-making. Analytic hierarchy process. - M.: Radio and Communications. (In Russian)

Stone, D. (2014).Cost Accounting Systems: A Holistic View from the Top //Global interdisciplinary business-economics advancement conference (GIBA) conference proceedings, 94-102.

Volochaeva, Y.I., Nagulina I.V. (2013). Improvement of methodological approaches to the evaluation of labor efficiency. Annals of the Belgorod University of Cooperation, Economics and Law, 4 (48): 421-427. (In Russian)

Womak, J., Jones, D., \& Adler, Y. (2004). Lean manufacturing: How to eliminate losses and to achieve prosperity of your company.

Zimakova, L.A. Kovalevskaja, A.V., S.N. Kovalenko, S.P. Mashirova and N.I. Bykanova (2016). Phases of Evaluation of Projected Financial Results from Ordinary Activities of a Manufacturing Company. International Business Management, 10 (16): 33323337.

Zimakova, L.A., Shtefan, Y.G. (2017).Some elements of management cost accounting system in meat processing companies that implement lean manufacturing. Belgorod State University Scientific bulletin. Ser. Economics. Information Technologies, № 2(251), Iss. 41: 38-45. (In Russian)

\section{How to cite this article:}

Shtefan Y G, Zimakova L A, S N, Peresypkina N N. Application of quantitative and qualitative methods for determination of priority development directions of companies implementing lean manufacturing. J. Fundam. Appl. Sci., 2017, 9(1S), 948-959. 